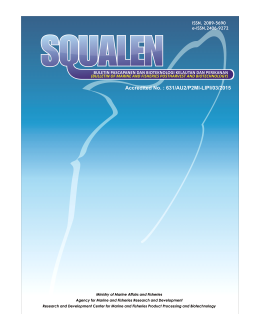

\title{
Metabolite Profiles and Antioxidant Activity of Caulerpa racemosa with Different Handlings

\author{
Sihono ${ }^{1,2}$, Kustiariyah Tarman ${ }^{3,4}$, Hawis Madduppa ${ }^{4}$, and Hedi Indra Januar ${ }^{2}$ \\ ${ }^{1}$ Department of Aquatic Product Technology, Bogor Agricultural University \\ Jalan Agatis, Babakan, Dramaga, Bogor, Jawa Barat 16680, Indonesia \\ 2 Research and Development Center for Marine and Fisheries Product Processing and Biotechnology, \\ Jalan K.S. Tubun, Petamburan VI, Slipi, Jakarta Pusat 10260, Indonesia \\ ${ }^{3}$ Department of Marine Science and Technology, Bogor Agricultural University, \\ Jalan Agatis, Babakan, Dramaga, Bogor, Jawa Barat 16680, Indonesia \\ ${ }^{4}$ Division of Marine Biotechnology, Center for Coastal and Marine Resources Studies,
} \\ Bogor Agricultural University, Jl. Raya Pajajaran, Baranangsiang, Bogor, Jawa Barat 16127, Indonesia
}

Article history:

Received: 4 July 2018; Revised: 30 October 2018; Accepted: 29 November 2018

\begin{abstract}
Metabolite profiles and antioxidant activity of Caulerpa racemosa extract with different handlings were investigated. Three different handlings during transportation were applied, namely samples chilled with ice, stored in liquid nitrogen and soaked in seawater. The different handling significantly affected the yield of ethanolic crude extracts and inorganic fractions but insignificantly to organic fractions. Different handlings resulted in differences of major fractions of $C$. racemosa extracts. Major fractions of the sample that was handled with chilling temperature contained low polar fractions $\left(\mathrm{K}_{10}, \mathrm{~K}_{11}, \mathrm{~K}_{12}\right.$, and $\left.\mathrm{K}_{13}\right)$, while seawater handling extract contained very polar $\left(\mathrm{K}_{1}, \mathrm{~K}_{2}\right.$ and $\left.\mathrm{K}_{3}\right)$, polar $\left(\mathrm{K}_{6}, \mathrm{~K}_{7}\right.$, and $\left.\mathrm{K}_{8}\right)$ and low polar $\left(\mathrm{K}_{13}\right)$ fractions. The extract of the sample handled in liquid nitrogen contained balanced fractions. Chilling temperature handling produced highest antioxidant activity ( $\mathrm{IC}_{50}$ below 2,000 ppm) in ethanolic extract of $C$. racemosa.
\end{abstract}

Keywords: antioxidant activity, Caulerpa racemosa, ethanolic extract,handlings, $I C_{50}$

\section{Introduction}

Caulerpa racemosa, also known as sea grape, is a species of Chlorophyta that commonly found in lower intertidal and upper subtidal areas which waves and currents action were not strong. The algae lives in habitats with sandy-muddy to rocky-coralline substrates and it is generally distributed in tropical and subtropical marines of Phillipines, Vietnam, Singapore, Malaysia, Thailand, Taiwan, China, Indonesia, and Western Pacific Islands. Sea grape is used for human consumption, eaten fresh or in a saltpreserved form in Japan, Korea, Philippines and other Southeast Asia countries. It is known as a source of active compounds such as caulerpin and caulerpicin. Caulerpin is an active compound with anesthetic activities, while caulerpicin used for medication (antifungal and lowers blood pressure) because of its toxic effect (FAO, 2018).

Secondary metabolites with various categories of natural products such indol derivatives, indan derivatives, sesquiterpenoid derivatives, diphenyl pentadiene derivatives, terpenoids and fatty acids were identified in ethanolic extract of $C$. racemosa (Ornano, Serafini, Sanna, \& Bianco, 2014). Various secondary metabolite compounds contained in $C$. racemosa including pseudoephedrine, 5-butyl-2-methyl- $\delta 1$ pyrrolidine, 2-myristynoyl pantetheine, tetracontane, deoxyspergualin, hexyl octyl ether (Rahul et al., 2014), phenol, saponin, tannin, flavonoid, reduce sugar, xanthoprotein (Azhagu, Mala, \& Prakasam, 2015), sesquiterpenoid and diterpenoid, $\beta$-sitosterol, caulerpin, caulerpenin (Gaillande, Payri, Remoissenet,

${ }^{*}$ Corresponding author.

E-mail: sihono2011@gmail.com 
\& Zubia, 2016), catechin epigallo (Yoshie, Wang, Petillo, \& Suzuki, 2000). The secondary metabolite compounds of $C$. racemosa extract have potential usage as antimicrobial compounds against Gramnegative, Gram-positive and pathogenic fungi (Etcherla \& Rao, 2014), antimicrobials against Escherichia coli, Staphylococcus aureus, Streptococcus sp, Salmonellasp (Perez, Falque, \& Domínguez, 2016) Vibrio harveyi (Ikbal, 2015), antioxidants (Chew, Lim, Omar, \& Khoo, 2008), antiherpes (Ghosh et al., 2004), antitumor (Ayyad \& Badria, 1994), anticoagulants and antivirals (Rahul et al., 2014).

Caulerpa racemosa has a high moisture content $(88.8-91.5 \%)$ so that this commodity is very easily decreased in quality after harvesting process and require immediate processing or preservation (Siah, Aminah, \& Ishak, 2013). Bioactive substances in plant materials can be damaged during handling, pretreatment, processing, drying, extraction, and longterm storage (Mediani, Abas, Tan, \& Khatib, 2014). Drying is an eminent method in handling seaweed. Drying will reduce the water activity. Thus inhibits microbial growth, extend shelflife and reduce the volume of seaweeds (Gupta, Cox, \& Ghannam, 2011). Unfortunately, the drying method could not be applied to $C$. racemosa, as the quality parameters of $C$. racemosa are the freshness of the thallus, bright green color, and compact texture that indicate the turgor pressure in the cell is still good (IMR, 2012). Drying will change the physical characteristics and active ingredients in seaweeds and resulted in a drastic reduction in the total phenol content and antioxidant activity (Ascorbic acid equivalent antioxidant capacity and ferric reducing power) (Chan et al., 2009). Drying at $25^{\circ} \mathrm{C}$ causes a decrease in the total phenol and flavonoid content of $49-51 \%$ compared to fresh seaweeds. DPPH scavenging ability of fresh seaweeds is higher than dry seaweeds (Gupta et al., 2011).

The appropriate handling of $C$. racemosa is needed to maintain physical quality and bioactive compounds. The handlings in this study were done by chilling the $C$. racemosa with ice, soaking in seawater and storing in liquid nitrogen. Freezing temperature would preserve the content of several bioactive compounds such as anthocyanin, hydrocinnamic acid, phenol and their antioxidative activity (Oszmian, Wolniak, Wojdyo, \& Wawer, 2008; Rapisarda, Bianco, Pannuzzo, \&Timpanaro, 2008). Storage at ultra-low temperature in liquid nitrogen $\left(-196^{\circ} \mathrm{C}\right)$ cause process of metabolic, biochemical, cell division, and most physical quality completely preserved, therefore plant material can be stored for long time (Kalaiselvi, Rajasekar, \& Gomathi, 2017).
Handling with liquid nitrogen has technical limitations as it could not be applied for large samples. Therefore, it is necessary to find alternative of handling method to preserve the bioactive compounds in $C$. racemosa. Handling by using chilling temperature and storing in seawater is an alternative to overcome the limitation of liquid nitrogen handling. By handling using a chilling temperature of $5^{\circ} \mathrm{C}$, the total phenol content and antioxidant activity can be maintained at $95 \%$ (Ali et al., 2018). The storage of seaweeds was more partical when using seawater and cold temperatures (Tiwari \& Troy, 2015). Handling by soaking seaweed in seawater aimed to keep it under particularly same condition of its habitat. Hopefully, no changes occur during transportation. The objective of this study was to investigate the effects of different handlings on the metabolic profiles and antioxidant activity of C.racemosa ethanolic extracts.

\section{Materials and Methods}

Technical grade ethanol (96\%), 1,1-Diphenyl-2picrylhydrazyl (DPPH) was purchased from Tokyo Kasei Kogyo Co., Ltd. (Tokyo, Japan), methanol (Merck), acetonitrile LC grade (Merck), water was deionized using a Milli- $Q$ water purification system from Millipore (Bedford, MA, USA).

\subsection{Sample Collection}

The Caulerpa racemosa used in this study was collected on 18 January 2018 from the rocky-coralline intertidal area of Binuangeun Coast in Banten Province (6 $\left.6^{\circ} 50^{\prime} 40^{\prime \prime} \mathrm{S}, 105^{\circ} 53^{\prime} 30^{\prime \prime} \mathrm{E}\right)$. The sample was washed with seawater to remove the dirt and impurities. The collected samples were transported to laboratory within 8 hours and was handled in three ways; chilled with ice, stored in seawater, and stored in liquid nitrogen. Chilled with ice handling and seawater handling used coolbox to place the samples, while in liquid nitrogen handling the samples placed in the conical tube and immersed in liquid nitrogen container.

\subsection{Preparation of Ethanolic Extracts}

Approximatelly $50 \mathrm{~g}$ of fresh sample was extracted using $500 \mathrm{~mL}$ ethanol (96\%) for 24 hours at room temperature then filtered using Whatman no. 42 to obtain crude extracts. The extracts were evaporated under low pressure and then freeze-dried to remove residual solvent. Ethanolic extract was resuspended with methanol and passed through solid phase extraction (SPE) using silica column $\left(\mathrm{C}_{18}\right)$ to remove inorganic and salt contents. The retained fraction in 
SPE was called inorganic fraction that contained salts and an inorganic component. The collected fraction that passes through the SPE was called organic fraction.The organic phase was subsequently evaporated to dry and stored in $-20^{\circ} \mathrm{C}$ until use. Each method was analyzed in triplicate.

\subsection{DPPH Radical-Scavenging Activity of Antioxidant Extract}

Antioxidant evaluation of $C$. racemosa crude extract was conducted using 1,1-diphenyl-2picrylhydrazyl radical (DPPH) method according to Sachindra et al. (2007) with some modifications. DPPH reagent (Merck) was prepared by diluting $3 \mathrm{mg}$ in 5 $\mathrm{mL} \mathrm{MeOH} \mathrm{(p.a).} \mathrm{A} \mathrm{methanol} \mathrm{diluted} \mathrm{seaweed} \mathrm{dry}$ extract of $160 \mu \mathrm{L}$ was poured into 96 -well microplate then a $40 \mu \mathrm{L}$ of DPPH reagent was added (A). Extract control (containing $160 \mu \mathrm{L}$ of seaweed extract and 40 $\mu \mathrm{L}$ of $\mathrm{MeOH})(\mathrm{B})$, negative control $(160 \mu \mathrm{L} \mathrm{MeOH}$ and $40 \mu \mathrm{L}$ of DPPH reagent) (C) and a blank $(200 \mu \mathrm{L} \mathrm{MeOH})$ (D) were also used in this evaluation. The mixture was incubated at $25-28^{\circ} \mathrm{C}$ for 30 minutes. Absorbance of each well was measured using microplate reader (Thermo Scientific) at $517 \mathrm{~nm}$. DPPH free radical inhibition percentage was calculated using the following equation: $[(C-D)-(A-B)] /(C-D) \times 100 \%$. Inhibition concentration $\left(\mathrm{IC}_{50}\right)$ value was calculated using probit analysis.

\subsection{Preparative HPLC Analysis}

The organic fraction of ethanolic extract was resuspended in methanol.The HPLC analysis was performed using Shimadzu LC-20A system model with UV-Vis detector and $\mathrm{C}_{18}$ column $(20 \mathrm{~mm} \times 250 \mathrm{~mm})$ Phenomenex (particle size $5 \mu \mathrm{m}$ ). The injection volume was $10 \mu \mathrm{L}$, and the sample was detected at $254 \mathrm{~nm}$. The mobile phase was composed of $100 \%$ water (solvent A) and $100 \%$ acetonitrile (solvent B). Linear gradient elution was performed from $20 \%$ solvent $B$ and $80 \%$ solvent $A(t=0 \mathrm{~min})$ to $100 \%$ solvent $B$ at $\mathrm{t}=30 \mathrm{~min}$. Total run time was $30 \mathrm{~min}$. The mobile phase was achieved at $15 \mathrm{~mL} / \mathrm{min}$ and the column temperature was $30^{\circ} \mathrm{C}$.

\subsection{Statistical Analysis}

DPPH measurement and HPLC analysis were carried out in three independent extractions and performed in triplicate for each extraction. Exploratory data analysis was done using box plots to visually summarize and compare groups of data. Computations were conducted by using SPSS Version 16.0 statistical software.

\section{Results and Discussion}

\subsection{Effect of Handling Methods on The Yield of Ethanolic Extracts}

The general principle of extraction using solvents is the compounds that extracted have similar polarity with the solvents (Zhang et al., 2007). We used a polar solvent, technical grade ethanol $(96 \%)$ to extract bioactive compounds in $C$. racemosa since other organic solvents like acetone, methanol, chloroform, and hexane are toxic for human consumption.

Figure 1 shows the effect of handlings on crude extracts, organic and inorganic content in $C$. racemosa extract. Crude extracts were composed of organic and inorganic fractions. The differences in handlings were significantly affected on crude extracts and inorganic fractions, but not significant on the content of organic fractions. Liquid nitrogen handling resulted in yield of extract where the yield of crude extracts and inorganic fractions was higher than the other handlings. According to the results, inorganic fraction content plays a role in determining the amount of the crude extract yield.

The yield of extraction depends on the polarity of solvent, extraction process ( $\mathrm{pH}$, temperature, time), and sample compositions. Polarity of solvent and sample constituents is the main condition parameters for extraction process under the same time and temperature (Stalikas, 2007). Organic fractions content in C. racemosa extract was $0.8-1.0 \%$ (Nagappan \& Vairappan, 2013). Ethanol extracts from marine biota have high salt content. The salt content of fresh $C$. racemosawas $4.0 \pm 0.2 \%$. That was rapidly decreased when soaked in 50 to $150 \mathrm{~mL}$ of aquades at $26^{\circ} \mathrm{C}$ for $30 \mathrm{~min}$. Later, it was gradually reduced to $1.2 \pm 0.1 \%$ when the volume of aquades was rose to $250 \mathrm{~mL}$ (Nguyen, 2016).

Liquid nitrogen made the sample freezing quickly at the temperature of $-196{ }^{\circ} \mathrm{C}$ causing salts and inorganic compounds trapped inside the cell and carried out with crude extracts during extraction process. During chilling temperature handling, some ice melted and carried liquid cells that contained salts and inorganic compounds resulting in the decreased of inorganic fractions of crude extract. Seawater handling aimed to maintain the same condition as the $C$. racemosas habitat, and no changes on compounds during transportation.

\subsection{Metabolite Profiles of Ethanolic Extract of C. racemosa}

The HPLC analysis was performed with a hydrophobic stationary phase $\left(\mathrm{C}_{18}\right)$ and HPLC grade water and acetonitrile phase with a gradient mode 


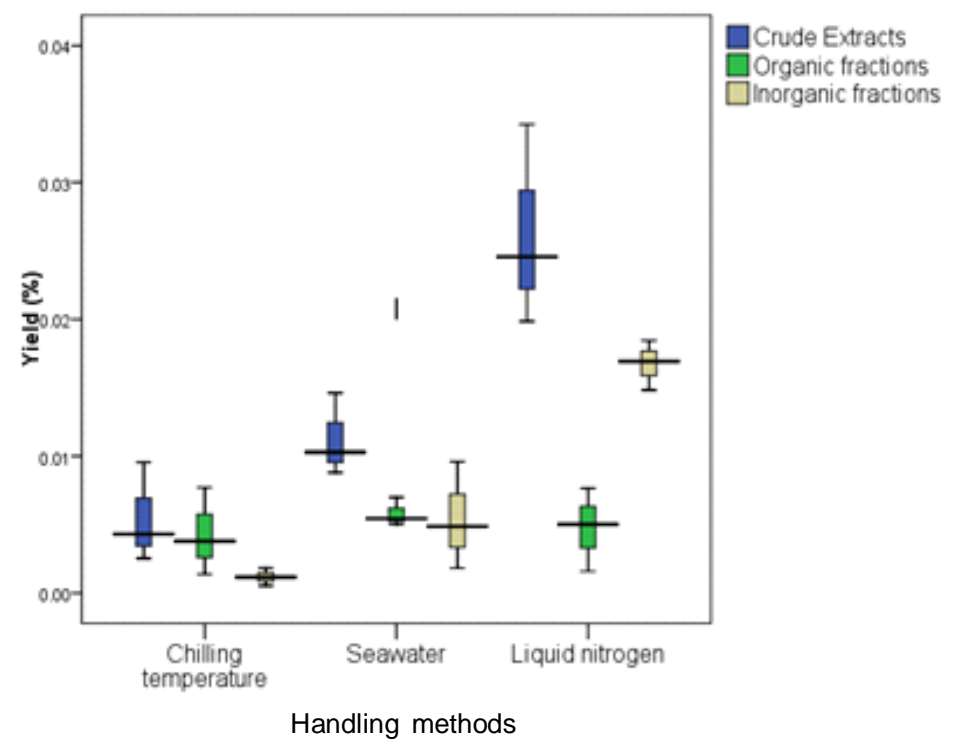

Figure 1. Effect of handling on ethanolic extract of C. racemosa

which elutes for 30 minutes. Ethanol extracts from marine biota have high salt content. Therefore, in the early stages of isolation the inorganic contents should be eliminated. The elimination was done by passing the extract on the SPE flash chromatography $\mathrm{C}_{18}$ column with the methanol mobile phase. Thereafter, the free extract of inorganic compounds was fractionated and isolated sequentially on preparative, semipreparative and analytical HPLC columns to obtain the target bioactive compound isolates. Reverse Phase HPLC has a broad range of selectivity coupled with a high degree of reproducibility. The retention time of RP-HPLC is longer for less polar molecules; as such, the polar molecules elute more readily (Abubakar, Salleh, Omar, \& Wagiran, 2017).

The chromatogram of $C$. racemosa extract with different handlings exhibited similar peak patterns and shapes to each others (Figure 2). The different handlings did not affect the diversity of bioactive compounds in $C$. racemosa extract. The retention time difference was affected by the degree of polarity of the compound, the chemical structure of the compound and the mobile phase of HPLC. The solvent extract used in the preparation of HPLC analysis was a polar pure methanol. At the beginning of the injection, the composition of the water mobile phase was greater than the acetonitrile mobile phase so that the polar compounds were detected earlier, while in the final stages of the injection, the acetonitrile composition was larger than water so that the compounds detected were less polar. The polarity of the compound influenced by the number of oxygen atoms and the length of the chain.
According to the peak and retention time, the quantity of major components in HPLC fractions was measured by dividing HPLC fractions into 13 major fractions namely with fractions of $\mathrm{K}_{1}, \mathrm{~K}_{2}, \mathrm{~K}_{3}, \mathrm{~K}_{4}, \mathrm{~K}_{5}$, $\mathrm{K}_{6}, \mathrm{~K}_{7}, \mathrm{~K}_{8}, \mathrm{~K}_{9}, \mathrm{~K}_{10}, \mathrm{~K}_{11}, \mathrm{~K}_{12}$, and $\mathrm{K}_{13}$. Each fraction was transferred into a microtube, removed the solvent by freeze-dried and weighted.

As shown in Figure 3, different handlings affected the major compounds in $C$. racemosa extract. Chilling temperature handling contained low polar fractions $\left(\mathrm{K}_{10}, \mathrm{~K}_{11}, \mathrm{~K}_{12}\right.$, and $\left.\mathrm{K}_{13}\right)$, Seawater handling contained very polar $\left(\mathrm{K}_{1}, \mathrm{~K}_{2}\right.$ and $\left.\mathrm{K}_{3}\right)$, polar $\left(\mathrm{K}_{6}, \mathrm{~K}_{7}\right.$ and $\left.\mathrm{K}_{8}\right)$ and low polar $\left(K_{13}\right)$ fractions, while the liquid nitrogen handling contained balanced fractions.

Marine organism contained various polarity metabolite compounds. Polar metabolites represented mainly by alkaloid salts, polyhydroxysteroids, saponins, amino acids and its derivates. The medium polarity metabolites were peptides and depsipeptides, while the low polarity metabolites were hydrocarbons, fatty acids, acetogenins, and terpenes (Riguera, 1997). Polarity of solvent and extraction conditions such as temperature and speed of agitation affect the extraction yield of total phenolic, total flavonoid and antioxidants (Muhamad, Gimbun, \& Yusoff, 2014). Polar solvents are frequently used for extracting polyphenols content in plant materials. Polyphenols extraction using ethanol as a solvent gave a high yield of total extract and antioxidant capacity, despite the fact that it was not highly selective for phenols extraction (Dai \& Mumper, 2010). Flavonoids and their glycosides, catechols, and tannins contained in plant materials were effectively extracted using ethanol 


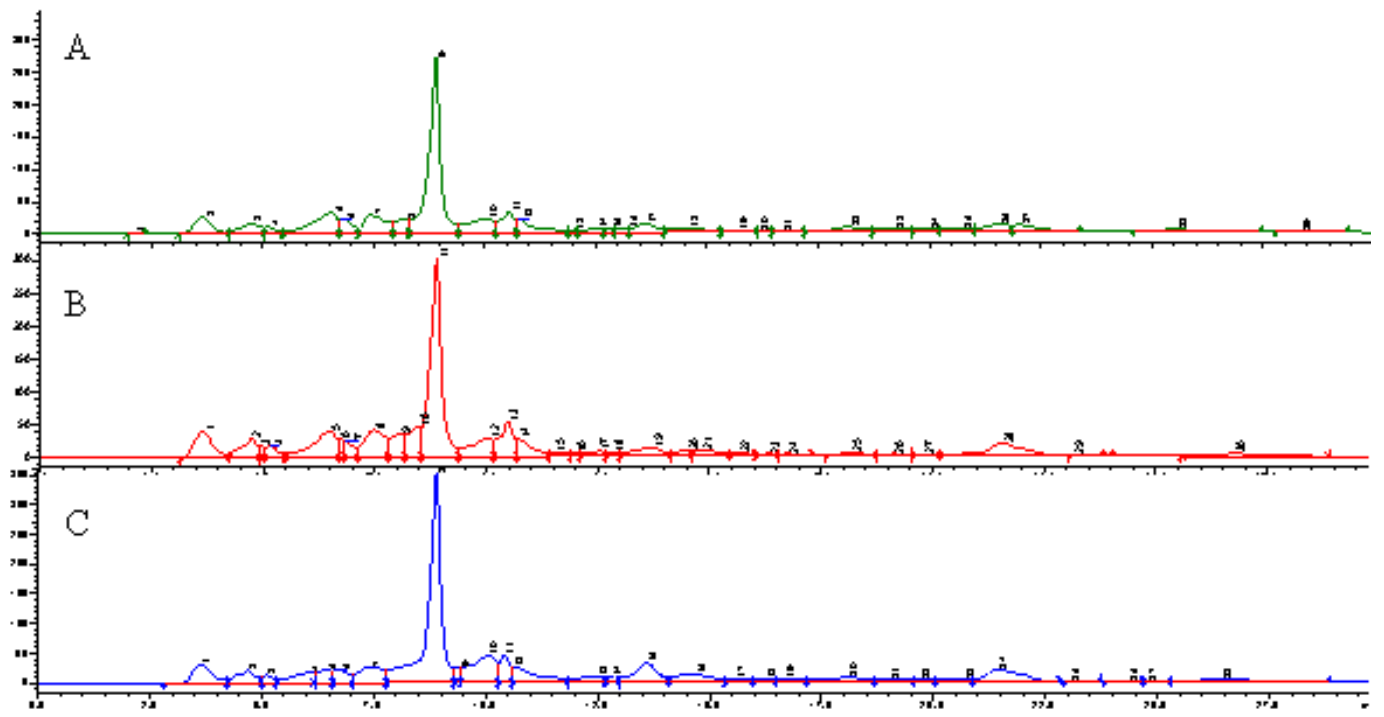

Figure 2. HPLC chromatogram profiles of different handlings of $C$. racemosa ethanolic extracts: $(A)$ : Chilling temperature, (B): Seawater, (C): Liquid Nitrogen

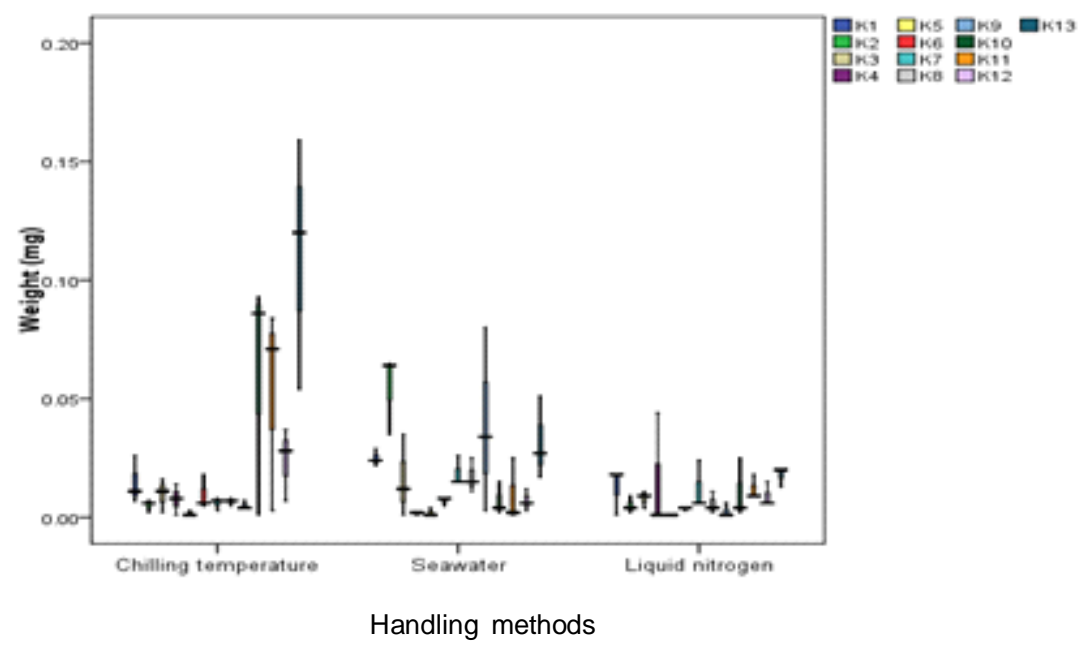

Figure 3. Effect of different handlings to the major compounds of $C$. racemosa ethanolic extract

(Bazykina, Nikolaevskii, Filippenko, \& Kaloerova, 2002).

\subsection{Effect of Handlings Methods on Antioxidant Activity}

The ethanolic extract of $C$. racemosa were evaluated for their antioxidant activity using DPPH radical scavenging activity method. It has been used extensively to evaluate antioxidant activity of substances to neutralize the free radical (Singh \& Rajini, 2004). Free-radical scavenger donor an electron or hydrogen to DPPH so it become diamagnetic molecule and paired off, reducing DPPH's ability to absorb colors. The free-radical scavenger capacity determined by the ability of the extract to reduce colors absorption ability of DPPH. The antioxidant activity of extract was measured by $\mathrm{IC}_{50}$ value, which is determinated from the linear regression of the \% inhibition versus the antioxidant extract concentration. $\mathrm{IC}_{50}$ value proportional to the antioxidant activity. (Middha, Usha, \& Pande, 2013).

Seaweeds were rich sources of polyphenolic antioxidants such as flavonols, catechins, and phlorotannins (Heo, Park, Lee, \& Jeon, 2005). Major compounds of $C$. racemosa ethanolic extract have various biological activities such as lowering the glucose level in blood, reduces inflammation or swelling, and protection against harmfull agents and 


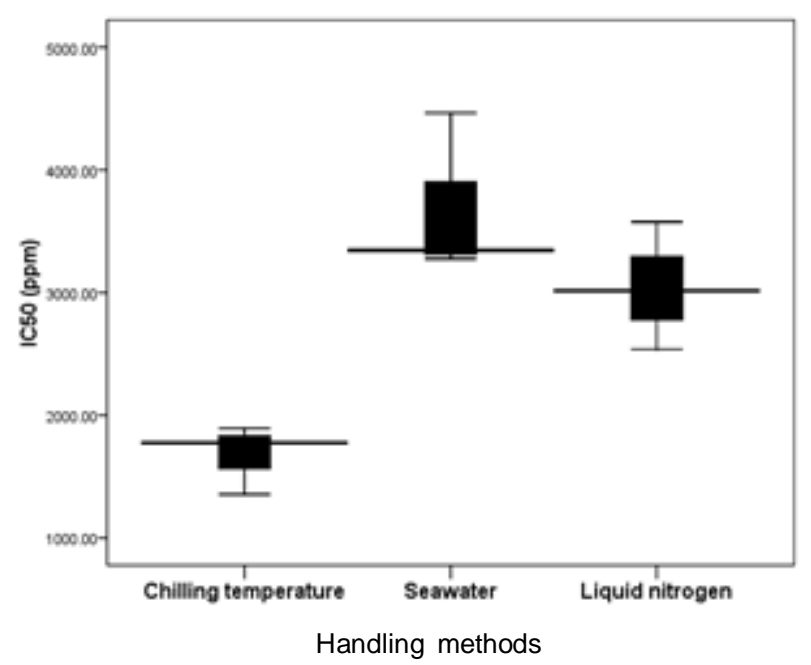

Figure 4. DPPH radical scavenging activity of ethanolic extract of $C$. racemosa.

free radicals. The active compounds were identified as myristynoyl pantetheine, tetracontane, deoxyspergualin, and hexyl octyl ether (Rahul et al., 2014).

Freezing would preserve the content of several bioactive components such as anthocyanin, hydrocinnamic acid, phenol and their antioxidative activity (Oszmian et al., 2008; Rapisarda et al., 2008). Liquid nitrogen protected photosynthetic pigment compounds and tocopherol (Esteban et al., 2009), carbohydrates, proline, phenol components including anthocyanins and flavonoids. Freezing maintained the ability of free radical scavenging capacity of antioxidant compounds. The content of polyphenolic or anthocyanin compounds has a correlation with the antioxidant activity of the material (Magdalena \& Macura, 2010).

As shown in Figure 4, different handlings were significantly affected the DPPH radical scavenging activity of ethanolic extract of $C$. racemosa. Chilling temperatures handling resulted in high antioxidant activity compared to the seawater and liquid nitrogen handling. According to the major compounds in the fractions, the compounds of $C$. racemosa extract with the strongest antioxidant activity in the DPPH assay were less polar.

According to the yield of ethanolic extract, extracts with chilling temperature handling had the smallest inorganic fractions content compared to handling with seawater and liquid nitrogen. Inorganic fractions may contain impurities and salts. There was a correlation between the content of inorganic fractions with antioxidant activity. Inorganic fractions in the extract will reduce the proportion of organic fractions that contain bioactive compounds and interfere with an active group in antioxidant structure, so the antioxidant activity of extract will be decreased.
$\mathrm{IC}_{50}$ values of extracts with different handling methods showed higher than $1,000 \mathrm{ppm}$. These values exceeded the $\mathrm{IC}_{50}$ maximum limit of a substance that could be called as having antioxidant activity, which is 200 ppm (Blois, 1958). Based on this limit, the antioxidant activity of $C$. racemosa extract tends to be less active. The same results were also shown in a study done by Dwihandita (2009) where the fresh sea grape extract had the best antioxidant activity with the smallest $I_{50}$ value of $1,115.94 \mathrm{ppm}$, while the dry seaweed extract have $I C_{50}$ value of $2,716.20$ ppm.

\section{Conclusion}

Chilling temperature handlings resulted in low inorganic fraction of the crude extract, which contain low polar metabolite fractions $\left(\mathrm{K}_{10}, \mathrm{~K}_{11}, \mathrm{~K}_{12}\right.$, and $\left.\mathrm{K}_{13}\right)$ and show the highest antioxidant activity. Therefore, this research suggests that the best way for maintaining the antioxidant activity of $C$. racemosa is by handling with chilling temperature.

\section{Acknowledgment}

This study was supported by Research and Development Center for Marine and Fisheries Product Processing and Biotechnology. The authors acknowledge the Ministry of Marines Affairs and Fisheries for the financial support.

\section{References}

Abubakar, B. M., Salleh, F. M., Omar, M.S.S., \& Wagiran, A. (2017). Review: DNA barcoding and chromatography fingerprints for the authentication of botanicals in herbal medicinal products. Hindawi, 2017, 1-29. doi: 10.1155/2017/1352948 
Ali, A., Chong, C.H., Mah, S.H., Abdullah, L.C., Choong, T.S.Y, \& Chua, B.L. (2018). Impact of storage conditions on the stability of predominant phenolic constituents and antioxidant activity of dried piper betle extracts. Molecules, 23(2), 1-15. doi: 10.3390/ molecules23020484

Ayyad, S.E.N., \& Badria, F.A. (1994). Caulerpin, an antitumor indole alkaloid from Caulerpa racemosa. Alex. J. Pharmacol. Sci., 8, 217-219.

Azhagu, R., Mala, K., \& Prakasam, A. (2015). Phytochemical analysis of marine macroalga Caulerpa racemosa (J.Agardh) (chlorophytacaulerpales) from Tiruneveli District, Tamilnadu, India. J. Glob. Biosci., 4(8), 3055-3067.

Bazykina, N.I., Nikolaevskii, A.N., Filippenko, T.A., \& Kaloerova, V. G. (2002). Optimization of conditions for the extraction of natural antioxidants from raw plant materials. J. Pharma. Chem., 36(2), 46-49. doi: 10.1023/A:1016024300843

Blois, M.S. (1958). Antioxidants determination by the use of a stable free radical. Nature, 4617, 1199-1200. doi: 10.1038/1811199a0

Chan, E.W.C., Lim, Y.Y., Wong, S.K., Lim, K.K., Tan, S.P., Lianto, F.S., \& Yong, M.Y. (2009). Effects of different drying methods on the antioxidant properties of leaves and tea of ginger species. Food Chemistry, 113(1), 166-172. doi: 10.1016/j.foodchem.2008.07.090

Chew, Y.L., Lim, Y.Y., Omar, M., \& Khoo, K.S. (2008). Antioxidant activity of three edible seaweeds from two areas in South East Asia. Food. Scie. and. Tech. 41(6), 1067-1072. doi: 10.1016/j.Iwt.2007.06.013

Dai, J., \& Mumper, R.J. (2010). Plant phenolics: extraction, analysis and their antioxidant and anticancer properties. Molecules, 15(10), 7313-7352. doi: $10.3390 /$ molecules 15107313

Dwihandita, N. (2009). Effect of processing on antixidant content of seagrape (Caulerpa racemosa). (Bachelor's thesis). Institut Pertanian Bogor, Bogor. Retrieved from https://repository.ipb.ac.id/handle/ $123456789 / 7467$.

Esteban, R., Balaguer, L., Manrique, E., Rubio de Casas, R.R., Ochoa, R., Fleck, I., .... Garcýa-Plazaola, J.I.G. (2009). Alternative methods for sampling and preservation of photosynthetic pigments and tocopherols in plant material from remote locations. Photosynth . Res., 101(1), 77-88. doi: 10.1007/ s11120-009-9468-5

Etcherla, M., \& Rao, G.M.N. (2014). In vitro study of antimicrobial activity in marine algae Caulerpa taxifolia and Caulerpa racemosa (C. agardh). Inter. J. Applied. Biol. and Pharmacol. Tech., 5(2), 57-62.

FAO (Food and Agriculture Organization)(1986). (2018, April 17). Seaweeds: Chlorophyta-green algae. Retrieved from http://www.fao.org/tempref/docrep/fao/ 009/w7191e/w7191e04.pdf.

Gaillande, C., Payri, C., Remoissenet, G., \& Zubia, M. (2016). Caulerpa consumption, nutritional value and farming in The Indo-Pacific Region. J. Appl. Phycol., 29, 2249-2266. doi: 10.1007/s10811-016-0912-6
Ghosh, P., Adhikari, U., Ghosal, P.K., Pujo,I.C.A., Carlucci, M.J., Damonte, E.B., \& Ray, B. (2004). In vitro antiherpetic activity of sulfated polysaccharide fractions from Caulerpa racemosa. Phytochemistry, 65(2004), 3151-3157. doi: 10.1016/j.phytochem.2004.07.025

Gupta, S., Cox, S., \& Ghannam, N. (2011). Effect of different drying temperatures on the moisture and phytochemical constituents of edible Irish brown seaweed. LWT-Food science Technology, 44(5),1266-1272. doi: 10.1016/j.Iwt.2010.12.022

Heo, S.J., Park, E.J., Lee, K.W., \& Jeon, Y.J. (2005). Antioxidant activities of enzymatic extracts from brown seaweeds. Biores Tech., 96(14), 1613-1623. doi: 10.1016/j.biortech.2004.07.013

Ikbal, M. (2015). Uji toksisitas ekstrak metanol rumput laut hijau (Caulerpa racemosa) pada larva udang Windu (Penaeus monodon). Octopus, Jurnal IImu Perikanan, 4(2), 417-421.

IMR (Institute of Marine Resources). (2012). Value adding and supply chain development for fisheries and aquaculture products in Fiji, Samoa and Tonga: Seagrapes post harvets and value addition in Fiji: Progress report. IMR Technical Report 06/2012, p. (pp. 1-18). Fiji: Lako, J.

Kalaiselvi, R., Rajasekar, M., \& Gomathu, S. (2017). Cryopreservation of plant materials - A review. Inter. J. Chem. Stud., 5(5), 560-564.

Magdalena, M., \& Macura, R. (2010). Effect of processing and storage on the antioxidant activity of frozen and pasteurized shadblow serviceberry (Amelanchier canadensis). Inter. J. Food Prop., 13(6), 1225-1233. doi: $10.1080 / 10942910903013407$

Mediani, A., Abas, F., Tan, C.P., \& Khatib, A. (2014). Effects of different drying methods and storage time on free radical scavenging activity and total phenolic content of Cosmos caudatus. Antioxidants, 3(2), 358-370. doi: 10.3390/antiox3020358

Middha, S.K., Usha, T., \& Pande, V. (2013). HPLC evaluation of phenolic profile, nutritive content, and antioxidant capacity of extracts obtained from Punica granatum fruit peel. Adv in Pharmacol Sci., 2013, 16. doi: $10.1155 / 2013 / 296236$

Muhamad, N., Gimbun, J., \& Yusoff, M. (2014). Influence of solvent polarity and conditions on extraction of antioxidant, flavonoids and phenolic content from Averrhoa bilimbi. J. Food Sci. and Eng., 4(2004), 255260. doi: 10.17265/2159-5828/2014.05.006

Nagappan, T., \& Vairappan, C. (2013). Nutritional and bioactive properties of three edible species of green algae, genus Caulerpa (Caulerpaceae). J. Applied. Phycol., 26, 1019-1027. doi: 10.1007/s10811-0130147-8

Nguyen, T. V. (2011). Analysis of proximate composition, total phenolic content, and antioxidant activity of seagrape. (Master's thesis). National Taiwan Ocean Univ. Retrieved from https://www.researchgate.net/ publication

Ornano, L., Serafini, M., Sanna, C., \& Bianco, A. (2014). Phytochemical study of Caulerpa racemosa (Forsk.) J. Agarth, an invading alga in the habitat of La 
Maddalena Archipelago. Nat. Prod. Res., 28(20), 1-5. doi: $10.1080 / 14786419.2014 .945928$

Oszmian, J., Wolniak, M., Wojdyo, A., \& Wawer, I. (2008). Influence of apple puree preparation and storage on polyphenol contents and antioxidant activity. Food. Chem., 107(4), 1473-1484. doi: 10.1016/ j.foodchem.2007.10.003

Perez, M.J., Falque, E., \& Domínguez, H. (2016). Review: Antimicrobial action of compounds from marine seaweed. Mar. Drugs., 14(3), 1-38. doi: 10.3390/ md14030052

Rahul, M., Suresh, N., Anil, T., Arun, M., Nivedita, G., \& Biware, M.V. (2014). GC-MS analysis of phytocomponents of seaweed, Caulerpa racemosa. Inter. J. Pharma. Res. \& Rev., 3(11), 39-45.

Rapisarda, P., Bianco, M., Pannuzzo, P., \& Timpanaro, N. (2008). Effect of cold storage on vitamin C, phenolics and antioxidant activity of five orange genotypes (Citrus sinensis (L.) Osbeck). Post. Bio. and Tech., 49(3), 348-354. doi: 10.1016/ j.postharvbio.2008.02.002

Riguera, R. (1997). Isolating bioactive compounds from marine organisms. J. Mar. Biotech., 5, 187-193.

Sachindra, N.M., Sato, E., Maeda, H., Hosokawa, M., Niwano, Y., Kohno., \& Miyashita, K. (2007). Radical scavenging and singlet oxygen quenching activity of marine carotenoid fucoxanthin and its metabolites.
J. Agri. Food. Chem., 55(21), 8516-8522. doi: 10.1021/jf071848a

Siah, W.M., Aminah, A., \& Ishak, A. (2013). Optimization of soaking conditions for the production of seaweed paste using reponse surface methodology. Inter. Food. Res. J., 21(1), 471- 477.

Singh, N., \& Rajini, P. S. (2004). Free radical scavenging activity of an aqueous extract of potato peel. Food. Chem., 85(4), 611-616. doi: 10.1016/ j.foodchem.2003.07.003

Stalikas, C.D. (2007). Extraction, separation, and detection methods for phenolic acids and ûavonoids. J. Sep. Sci., 30(18), 3268-3295. doi: 10.1002/ jssc. 200700261

Tiwari, BK., \& Troy, D. (2015). Seaweed sustainability: food and non food application, (pp 1-9). London: Academic Press.

Yoshie, Y., Wang, W., Petillo, D., \& Suzuki, T. (2000). Distribution of catechins in Japanese seaweeds. Fish. Sci., 66(5), 998-1000. doi: 10.1046/j.14442906.2000.00160.x

Zhang, Z., Li, D., Wang, L., Ozkan, N., Chen, X.D, Mao, Z, \& Yang, H. (2007). Optimization of ethanol-water extraction of lignans from flaxseed. J. Separation and Purification Tech., 57(1), 17-24. doi: 10.1016/ j.seppur.2007.03.006 